\title{
Nitriding of AISI 1020 Steel: Comparison Between Conventional Nitriding and Nitriding with Cathodic Cage
}

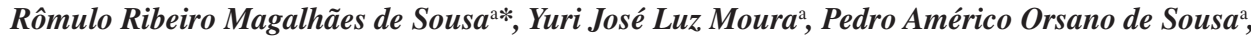 \\ José Quinzinho Medeiros Neto ${ }^{\mathrm{b}}$, Thércio Henrique de Carvalho Costac ${ }^{c}$ Clodomiro Alves Junior ${ }^{\mathrm{d}}$
}

${ }^{a}$ Laboratory Plasma - LabPlasma, Federal Institute of Education, Science and Technology of Piaui - IFPI, Pça da Liberdade, 1597, Centro, CEP 64000-040, Teresina, PI, Brazil

${ }^{\mathrm{b}}$ Laboratory Plasma - LabPlasma, Departament of Mechanical Engineer,

Federal University of Rio Grande do Norte - UFRN, Campus Universitário, Av. Sen. Salgado Filho, 3000, Lagoa Nova, CEP 59078-970, Natal, RN, Brazil

'Technology and Science School, Federal University of Rio Grande do Norte - UFRN, Campus Universitário, Av. Sen. Salgado Filho, 3000, Lagoa Nova, CEP 59078-970, Natal, RN, Brazil

${ }^{\mathrm{d}}$ Laboratory Plasma - LabPlasma, Departament of Physics, Federal University of Rio Grande do Norte - UFRN, Campus Universitário, Av. Sen. Salgado Filho, 3000, Lagoa Nova, CEP 59078-970, Natal, RN, Brazil

Received: August 26, 2013; Revised: January 21, 2014

\begin{abstract}
Cylindrical samples of AISI 1020 steel were nitrided, using the techniques of conventional plasma nitriding and cathodic cage. In the latter, the samples are kept at floating potential, inside of a cage that works as a cathode and to shield the samples from the cathodic potential. A systematic study was conducted in order to evaluate the efficiency of this technique in the elimination of edge effect, in comparison with conventional plasma nitriding. In addition, another comparative study of the phases obtained using the conventional plasma nitriding and nitriding with cathodic cage was performed. Two metallic cages were used, one made of austenitic stainless AISI 316 and other one made of AISI 1020 steel, to prove the effect of deposition in nitriding with cathodic cage. The samples which were nitrided by this new technique had shown nitriding rates, crystalline phases, and microhardness, similar to those samples which were nitrided conventionally. However, it was possible to confirm the elimination of edge effect through the characterization by optical microscopy and by microhardness test along the samples surfaces. The samples were characterized by optical microscopy, microhardness tests and X-ray diffraction.
\end{abstract}

Keywords: cathodic cage, plasma nitriding, SAE 1020 steel

\section{Introduction}

The conventional plasma nitriding (DCPN) is interesting for industries due to the important benefits in superficial properties. In comparison with others nitriding process (gas and salt bath) this is the most economic, permitting higher rate of nitrogen diffusion, in lower temperatures and shorter treatment times. The kinetic is higher than in gas nitriding because concentration gradient is formed quickly. The process has been successfully applied to steels of low alloy, tool steels and stainless steel ${ }^{1}$. It is used for improvements of surface properties such as hardness, resistance to wear and corrosion, with the goal of increasing the life of parts nitrided. However, it shows some drawbacks as edge effect, hollow cathode effect, non uniform temperature and opening of arches, especially in the treatment of parts with complex geometry ${ }^{2-4}$. In recent years, there arose an alternative technique, called ASPN (Active Screen plasma Nitriding) in which the samples are enclosed by a screen, where a high cathodic potential is applied. Thus the plasma acts on

*e-mail: romulorms@gmail.com the screen and not on the sample surface. The components to be treated are in a floating potential or subject to a low polarization voltage through an auxiliary source ${ }^{2}$. Since the plasma is not formed directly on the surface of the samples, but actually it is formed in the metal cage, the defects inherent to the DCPN process are eliminated ${ }^{5,6}$. Furthermore, the temperature at the surface of the samples is virtually uniform, since they are heated to the treatment temperature by radiation coming from the cathodic cage.

Based on the process of active screen, a new device called cathodic cage or cage ionizing (Deposit patent $\mathrm{n}^{\circ}$ PI 0603213-3) has been developed, with a well defined geometry, formed by plates with holes with well-defined diameters and distances in between to obtain uniform surface treatments enabling a wide range of industrial applications. With the goal to analyze the influence of the treatment temperature, samples of AISI 1020 steel were nitrided in cathodic cage with the following conditions: pressure of $350 \mathrm{~Pa}$, nitriding atmosphere of $80 \% \mathrm{~N} 2 / 20 \% \mathrm{H} 2$, 
temperatures of $673 \mathrm{~K}, 723 \mathrm{~K}$ and $753 \mathrm{~K}$. It is worth noting that this nitriding atmosphere allowed the formation of a compound layer for all the treatment temperatures.

\section{Material and Methods}

The material used in this study was an AISI 1020 steel, with composition provided in the Table 1

The treatment of the samples was performed on a system developed in the laboratory for processing materials by plasma (LabPlasma). This laboratory is located at IFPI (Federal Institute of Piaui State).

The samples were machined with a diameter of $12 \mathrm{~mm}$ and 5,8 and $10 \mathrm{~mm}$ in height to be used in nitridings treatments. In addition, all samples were grinded with 220 , 320, 400, 600, 1200 mesh sandpapers and they were polished using felt disks with alumina abrasives 1.0 and $0.3 \mu \mathrm{m}$. After that, they were cleaned using acetone, agitated by ultrasonic, before being placed in the nitriding chamber.

The cathodic cage Ion nitriding was performed in the same equipment used for the conventional nitriding. A continuous voltage source with $1200 \mathrm{~V}$ and $1 \mathrm{~A}$ maximum current was used. A device called cathodic cage (detail) was added in the cylindrical vaccum chamber (Figure 1). This chamber is $300 \mathrm{~mm}$ diameter and $300 \mathrm{~mm}$ in height, and it is made of stainless steel, the cage is made of AISI 1020 material. The cages have $45 \mathrm{~mm}$ diameter, $30 \mathrm{~mm}$ in height and $08 \mathrm{~mm}$ holes which are evenly distributed with $10 \mathrm{~mm}$ distance between adjacent holes. Furthermore, the cages were made by the company Houston Bike, one was fabricated using AISI 1020 steel, and the other one was made of AISI 316 steel.

In this configuration the plasma is formed in the cathodic cage, which acts as cathode (the chamber wall is the anode) rather than directly in the surface of the samples, placed above an alumina disc isolate, remaining in floating potential. All samples were pretreated in hydrogen atmosphere total with flow of $20 \mathrm{sccm}$, during 20 minutes, at $573 \mathrm{~K}$ and $200 \mathrm{~Pa}$, for the removal of surface oxides and/or oils. The samples were treated during 3 hours at temperature of 673,723 and $753 \mathrm{~K}$ at pressure of $350 \mathrm{~Pa}$. The nitriding atmosphere was composed of $80 \% \mathrm{~N} 2+20 \% \mathrm{H} 2$ in a total flow of $20 \mathrm{sccm}$. After treatment, the samples were cooled within the chamber under nitrogen flow until the temperature of $80{ }^{\circ} \mathrm{C}$, to reduce risks of oxidation.

After that, it was performed a microhardness test with aid of the Shimadzu microhardness, model HMV-2TE, with a load of $50 \mathrm{~g}$. Following they were cut and embedded using acrylic resin-A1 and liquid self-polymerizing-A2. The samples were grinded with 220, 320, 400, 600, 1200 mesh sandpapers, and polished with felt disks using alumina abrasives with 1.0 and $0.3 \mu \mathrm{m}$ and they were attacked with Nital $4 \%$, then the optical microscopy was performed.

This microscopy has used a microscope Nikon Japan coupled to a digital system for image to software Image-Pro Plus, which was used to obtain images, and measuring of the thickness of nitride layer. The X-ray diffraction measure took place at Federal University of Rio Grande do Norte State (UFRN), with geometry Brag-Brentano at diffraction device (SIEMENS D500) at following condition:

Table 1. Chemical composition of AISI 1020 steel.

\begin{tabular}{cccccc}
\hline Steel & \multicolumn{5}{c}{ Chemical composition (\% atomic) } \\
\hline AISI 1020 & $0.20 \% \mathrm{C}$ & $0.3 \% \mathrm{Mn}$ & $0.04 \% \mathrm{P}$ & $0.05 \% \mathrm{~S}$ & $\mathrm{Fe}$ \\
\hline
\end{tabular}

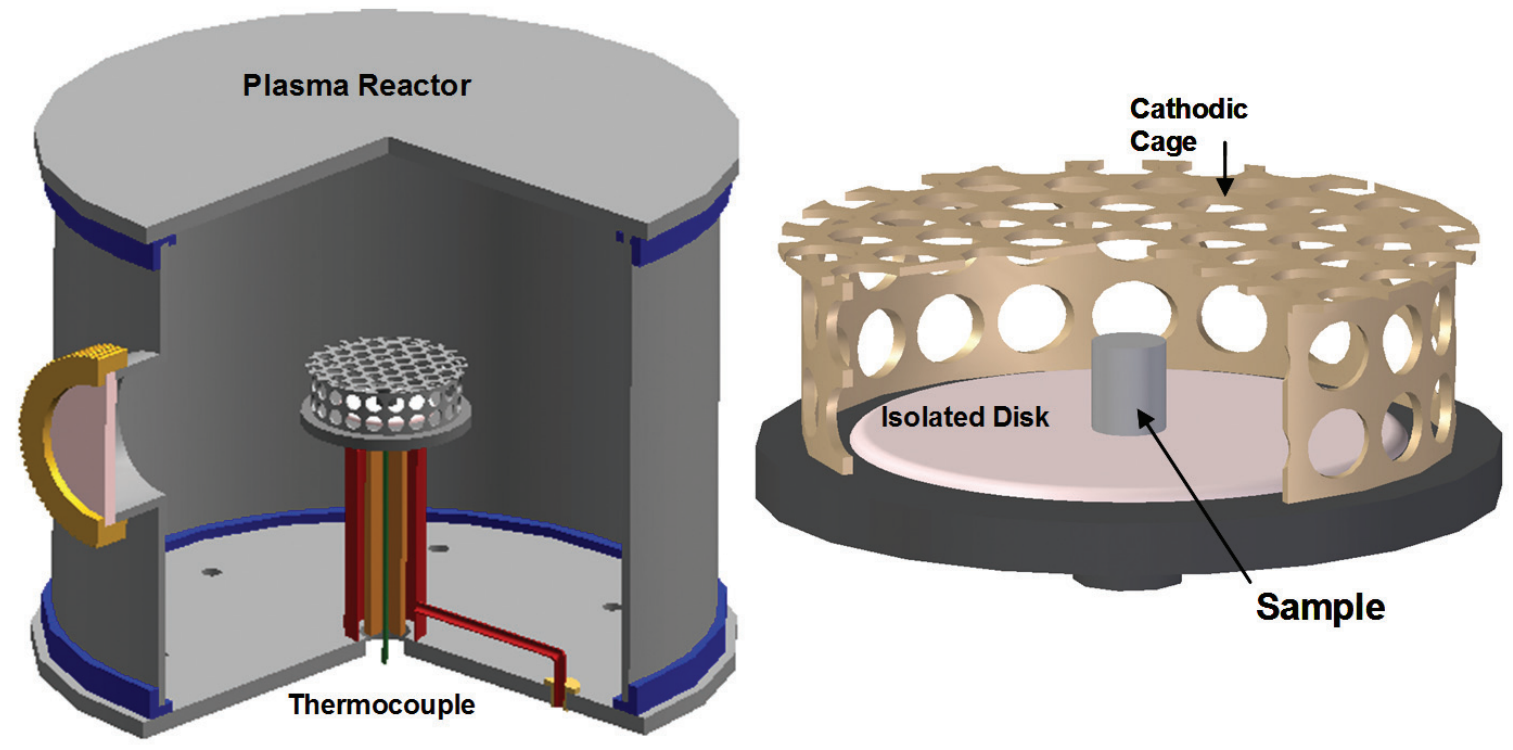

Figure 1. Sectional view of the reactor Ion nitriding, showing in detail the arrangement of samples in the cathodic cage. 
Radiation $\mathrm{Cu}-\mathrm{K} \alpha$, scanning angle $(2 \theta)$ : from 30 to $50^{\circ}$, advance angle: $0.02^{\circ}$ and time interval between advancements: $1.5 \mathrm{~s}$.

\section{Results}

\subsection{Microhardness}

The nitrided samples show that the conventional plasma nitriding (DCPN) produces a non-uniform surface layer, and its color varies from the center to the periphery of samples nitride $^{6,8}$. This phenomenon can be seen without microscope and it is known as edge effect that is a common problem associated with the DCPN process, triggered by competition between sputtering and deposition during the process, due to changes in the electric field in the corners and edges, as showed in the Figure 2a. And it may also be demonstrated through the variation of the microhardness along the surface of the nitrided piece 5 .

In Comparison, the nitriding in cathodic cage produces dark gray coloration, uniform that extends across the surface of samples, regardless of temperature and height of the samples. As the plasma is not formed directly on the samples surface, these one do not suffer sputtering active, thus the effects by edge effects are eliminated, as seen in the Figure $2 b$.

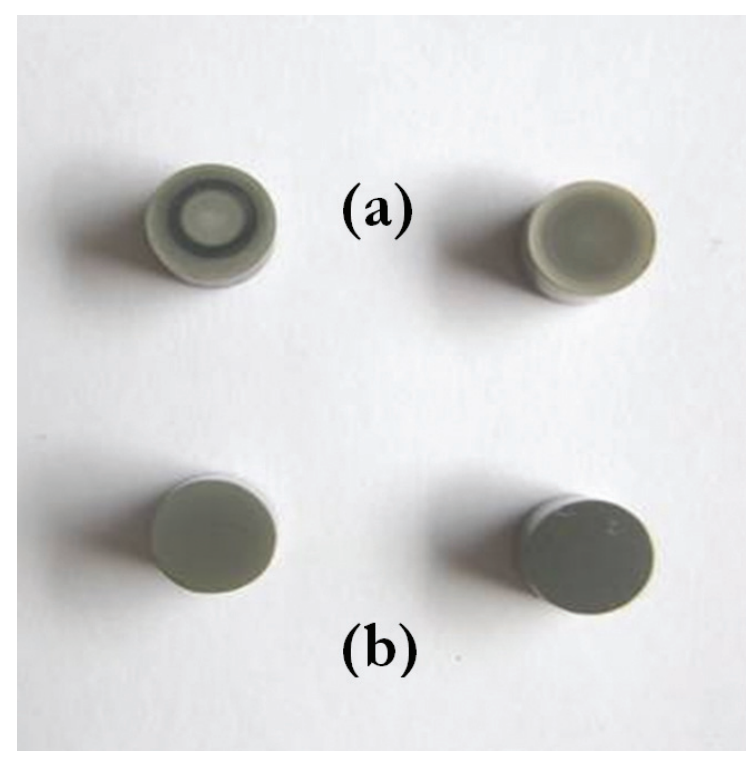

Figure 2. Edge effect (a) in DCPN and elimination of edge effect (b) in AISI 316 steel cathodic cage.
The microhardness measured along of the surface of samples processed by DCPN and NGC (nitriding in cathodic cage) are showed in the Table 2. The samples which were treated in DCPN technique have a region near from the edge where the nitrided surface hardness layer falls systematically. This characteristic is due to non-uniform sputtering that occurs due to the edge effect, Figure 3. The highest values (peaks) that appear at the edge of each treated sample at DCPN are related to thermal effects (greater heater) inherent to the technique, causing higher layers thicknesses in this type of compounds steel. On the other hand, the samples treated by NGC technique show complete hardness uniformity along the sample surface.

\subsection{Layer thickness}

Table 3 shows that the samples nitrided by the conventional technique present higher variation in layer thickness nitrided with height. The smallest variation of thickness in nitrided samples with cage is not due to the existence of thermal gradient, because the radiation from the cathodic cage provides the necessary heat to heat the samples evenly until the treatment temperature. In fact, this smallest variation is because the surfaces that are closer to the sputtering source (cage) achieve higher energy ${ }^{7,9}$.

It is worth noting that although the morphology and thickness of the nitreded layer are affected by time and nitriding temperature, the nitriding method by plasma (DCPN or nitriding with cathodic cage) does not have influence, both nitriding process by Plasma produce microstructure virtually similar, regardless of the samples' height (see Figure 4).

The layer thicknesses of compounds (Zc) and of the diffusion zone (Zd) of AISI 1020 steel nitrided are disposed in Table 4 below. The total layer thickness of nitrided samples in cathodic cage is higher than conventional technique.

It is worth noting that NGC of AISI 1020 steel is a nitriding in cathodic cage of AISI 1020 steel's samples, this procedure uses cage of AISI 1020 steel while NGC of AISI 316 is other procedure of nitriding in cathodic cage of AISI 1020 steel's samples that uses cage of AISI 316 steel.

\subsection{X-ray diffraction analysis}

Process of nitriding by conventional plasma DCPN and active screen NGC produce similar microstructures, according to x-ray analyses showed in Figures 5-8.

A detailed analysis of the spectra of $\mathrm{x}$-rays shows that nitrided $\gamma^{\prime}-\mathrm{Fe}_{4} \mathrm{~N}$ is present in larger amounts in all treated samples by DCPN when compared to NGC process. This effect is due to sputtering that occurs at the cathode, this is

Table 2. Microhardness AISI 1020 steel nitrided by conventional mode, in cathodic cage of AISI 1020 steel and of AISI 316.

\begin{tabular}{cccc}
\hline Temperature & \multicolumn{2}{c}{ Treatment } \\
\cline { 2 - 4 } & DCPN & $\begin{array}{c}\text { Nitriding in cathodic cage } \\
\text { of AISI 1020 Steel }\end{array}$ & $\begin{array}{c}\text { Nitriding in cathodic cage } \\
\text { of AISI 316 steel }\end{array}$ \\
\hline $673 \mathrm{~K}$ & $350-500 \mathrm{HV}$ & $320 \mathrm{HV}$ & $430 \mathrm{HV}$ \\
$723 \mathrm{~K}$ & $350-500 \mathrm{HV}$ & $415 \mathrm{HV}$ & $450 \mathrm{HV}$ \\
$753 \mathrm{~K}$ & $350-500 \mathrm{HV}$ & $450 \mathrm{HV}$ & $500 \mathrm{HV}$ \\
\hline
\end{tabular}



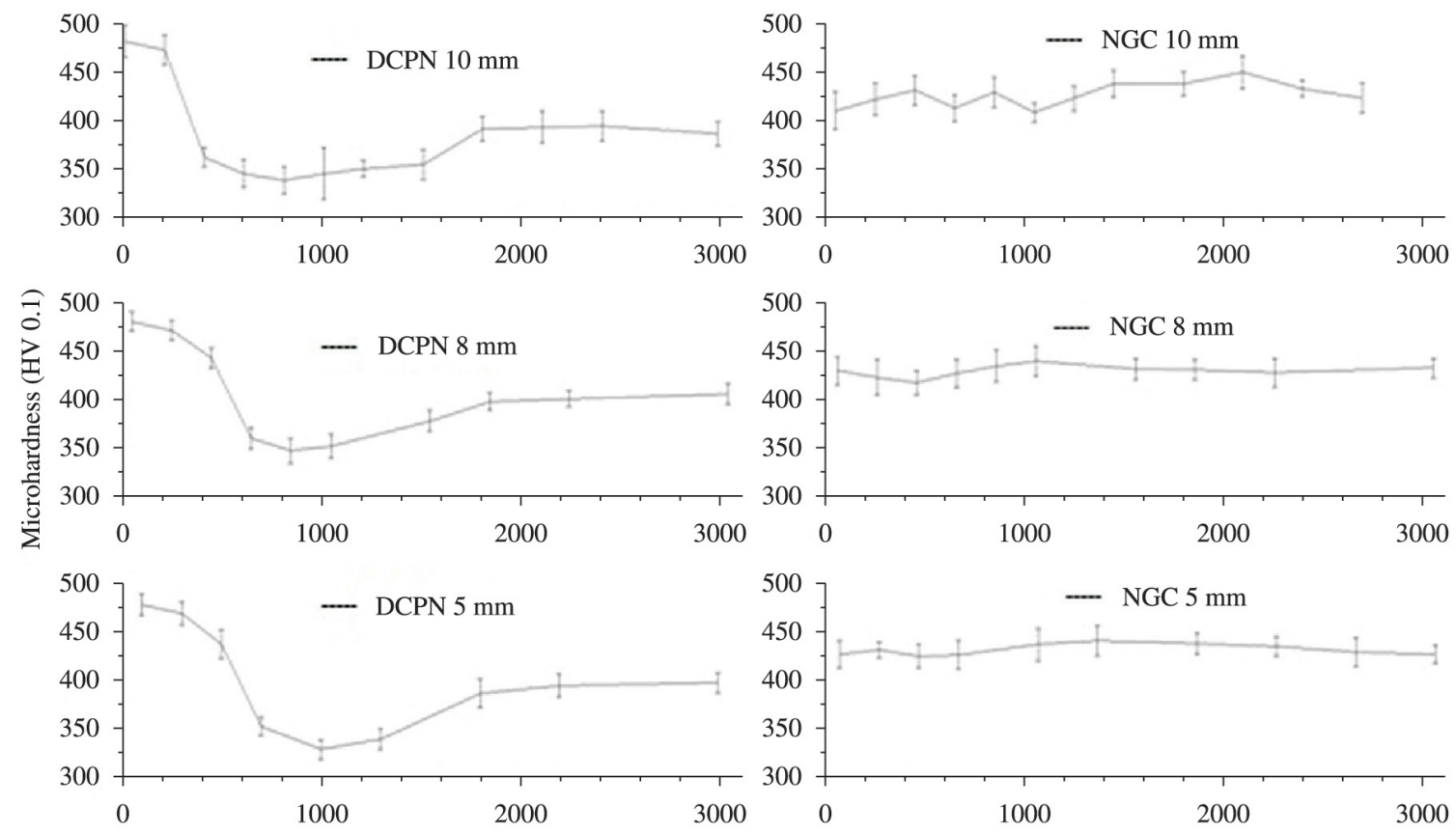

Distance from the edge to the center $(\mu \mathrm{m})$

Figure 3. Hardness in 1020 steel nitrided by DCPN and NGC process.

Table 3. Comparative table of layer thickness of compounds for samples of 5,8 and $10 \mathrm{~mm}$ high, nitrided by conventional mode and in cathodic cages at temperature of $753 \mathrm{~K}$.

\begin{tabular}{ccccc}
\hline $\begin{array}{c}\text { Sample height } \\
(\mathbf{m m})\end{array}$ & Temperature $(\mathbf{K})$ & $\begin{array}{c}\text { Compound layer } \\
(\text { Conventional nitriding) } \\
(\mu \mathbf{m})\end{array}$ & $\begin{array}{c}\text { Compound layer (Nitriding } \\
\text { in cathodic cage of } \\
\text { AISI 1020 steel) }(\mu \mathbf{m})\end{array}$ & $\begin{array}{c}\text { Compound layer (Nitriding } \\
\text { in cathodic cage AISI } \\
\text { 316 stainless steel) }(\mu \mathbf{m})\end{array}$ \\
\hline 5 & & 2.5 & 3.2 & 4.3 \\
8 & 753 & 4.5 & 3.5 & 5.0 \\
10 & & 5.0 & 4.1 & 5.8 \\
\hline
\end{tabular}

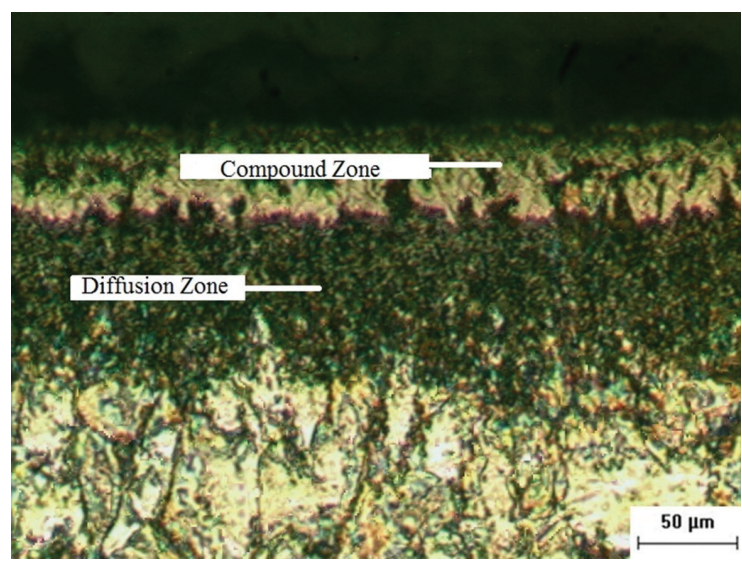

Figure 4. AISI 1020 steel nitrided in cathodic cage.

an inherent effect to the DCPN process. According to Ruset, 2003, the sputtering causes superficial decarburization in nitrided steels, providing the stabilization of the nitride $\gamma^{\prime}-\mathrm{Fe}_{4} \mathrm{~N}$. In the DCPN process of low alloy steels $(0.26 \mathrm{C}$, $3.44 \mathrm{Cr}, 0.54 \mathrm{Mo}$ and $0.48 \mathrm{Mn}) \varepsilon-\mathrm{Fe}_{2-3} \mathrm{~N}$ nitrides intensity are slightly smaller than those of $\gamma^{\prime}-\mathrm{Fe}_{4} \mathrm{~N}$, the relative intensity between the phases I $\varepsilon / \mathrm{I} \gamma$ values $0.97^{[7]}$.

In the NGC technique, as sputtering at the samples surface is minimized (intense sputtering occurs on active screen), there is no superficial decarburization and it provides formation of nitride $\varepsilon-\mathrm{Fe}_{2-3} \mathrm{~N}$, as in Figures 5-8. Peaks of $\gamma^{\prime}-\mathrm{Fe}_{4} \mathrm{~N}$ were smaller in NGC process, in this case the relative intensity between phases I $/$ /I $\gamma$ increased to $5.97^{[7]}$.

In the nitrided samples in DCPN as the samples' height increases the phase $\varepsilon-\mathrm{Fe}_{2-3} \mathrm{~N}$ becomes more stable. As the percentage weight of nitrogen in $\varepsilon-\mathrm{Fe}_{2-3} \mathrm{~N}$ (7.7 to $\left.11 \%\right)$ is higher than in $\gamma^{\prime}-\mathrm{Fe}_{4} \mathrm{~N}(5.9 \%)$, the NGC process has the highest concentration of superficial nitrogens. It shows that there is an increasing at superficial temperatures in samples with higher heights.

In the samples which were treated by NGC as show in Figures 5-7 there are no variation in the relative intensities of peaks $\varepsilon, \gamma^{\prime}$ and $\varepsilon+\gamma$, due to the higher temperature uniformity over the samples. The x-ray spectra of the NGC process with cage of 316 steel present peaks of $\mathrm{Fe}$ associated with $\mathrm{Cr}$, the presence of $\mathrm{Cr}$ element is due to the fact that 
Table 4. Layer thickness of compounds and of diffusion zone of nitrided samples in temperatures of 673, 723 and $753 \mathrm{~K}$.

\begin{tabular}{|c|c|c|c|c|c|c|c|c|c|c|}
\hline \multirow{2}{*}{$\begin{array}{c}\text { Sample } \\
(\mathrm{mm})\end{array}$} & \multirow[t]{2}{*}{ Technique } & \multicolumn{3}{|c|}{$673 \mathrm{~K} / 350 \mathrm{~Pa}$} & \multicolumn{3}{|c|}{723 K / $350 \mathrm{~Pa}$} & \multicolumn{3}{|c|}{$753 \mathrm{~K} / 350 \mathrm{~Pa}$} \\
\hline & & $\mathbf{Z c}(\mu \mathbf{m})$ & $\mathbf{Z d}(\mu \mathbf{m})$ & Total & $\mathbf{Z c}(\mu \mathbf{m})$ & $\mathbf{Z d}(\mu \mathbf{m})$ & Total & $\mathrm{Zc}(\mu \mathbf{m})$ & $\mathbf{Z d}(\mu \mathbf{m})$ & Total \\
\hline \multirow[t]{3}{*}{8} & DCPN & 3.3 & 27.0 & 30.3 & 3.9 & 35.0 & 38.9 & 4.5 & 54.0 & 58.5 \\
\hline & $\begin{array}{l}\text { NGC of AISI } \\
1020 \text { steel }\end{array}$ & 2.5 & 117.0 & 119.5 & 2.8 & 131.0 & 133.8 & 3.5 & 143.5 & 147.0 \\
\hline & $\begin{array}{l}\text { NGC of AISI } \\
316 \text { steel }\end{array}$ & 1.3 & 127.2 & 128.5 & 3.0 & 145.0 & 148.0 & 5.0 & 167.0 & 172.0 \\
\hline
\end{tabular}
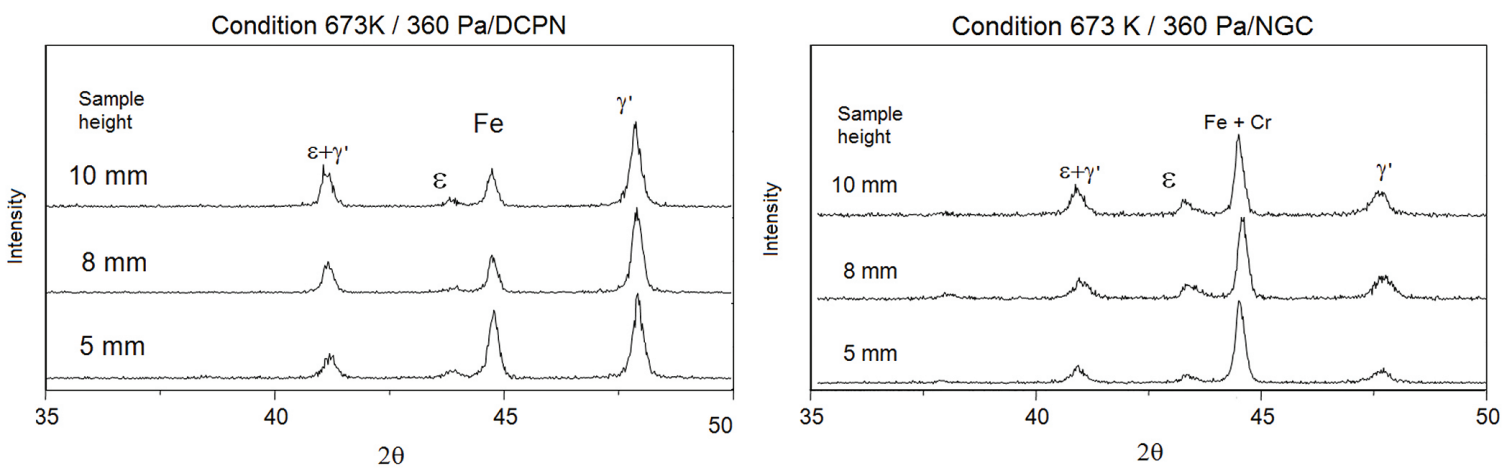

Figure 5. X-ray diffraction patterns of the samples nitrided at $673 \mathrm{~K} / 360 \mathrm{~Pa}$.

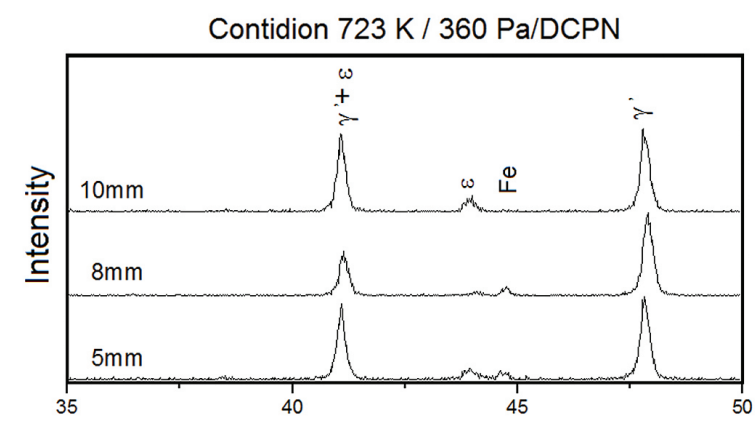

$2 \theta$

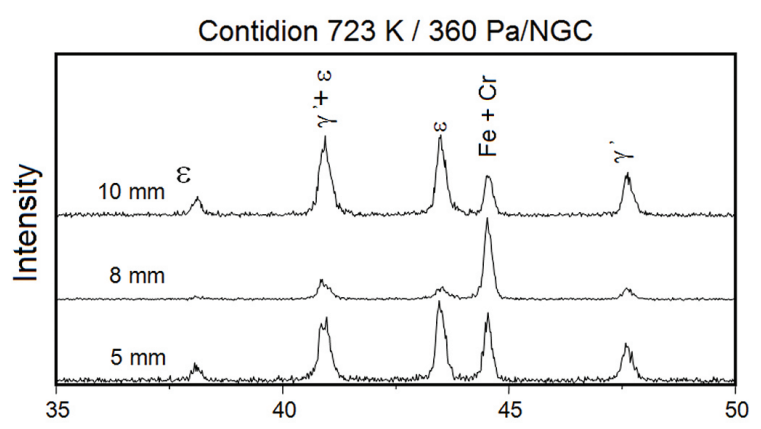

$2 \theta$

Figure 6. X-ray diffraction patterns of the samples nitrided at $723 \mathrm{~K} / 360 \mathrm{~Pa}$.
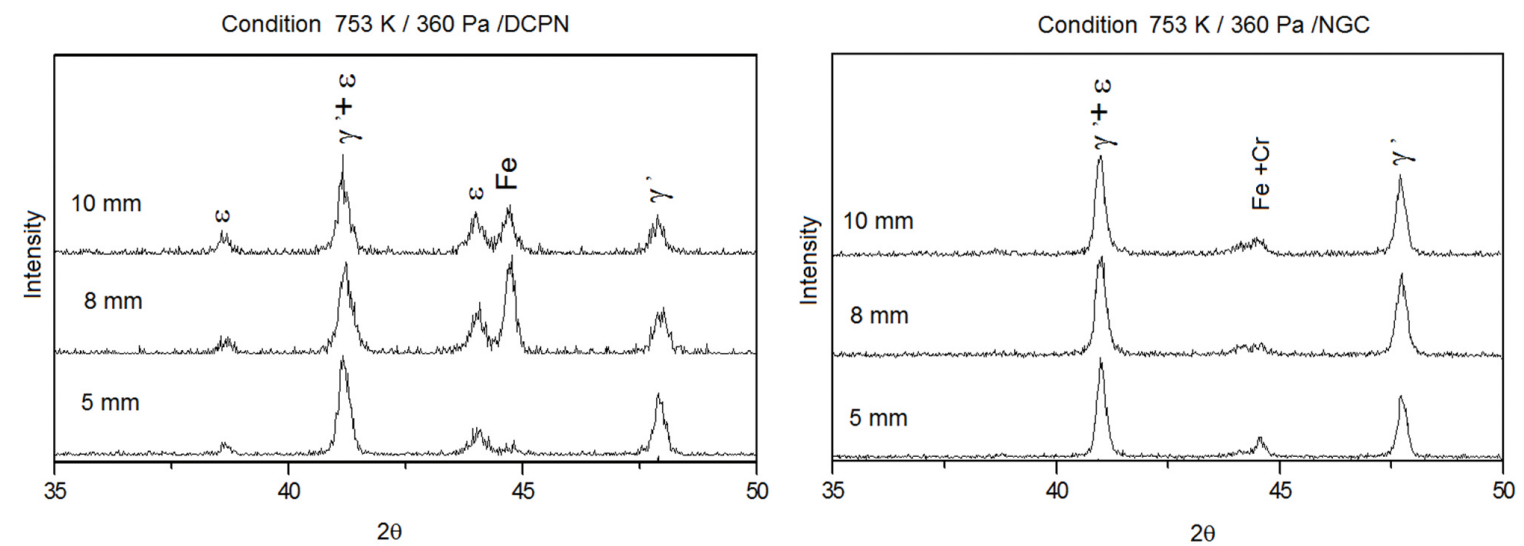

Figure 7. X-ray diffraction patterns of the samples nitrided in AISI 316 steel cathodic cage at 753K / $360 \mathrm{~Pa}$. 


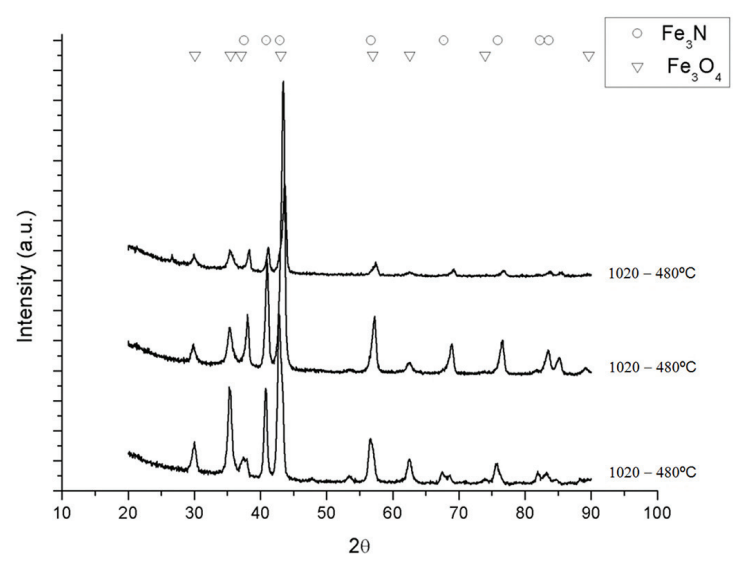

Figure 8. Nitrided samples diffraction patterns using AISI 1020 steel cage.

the active screen was made of stainless steel. For nitrided samples with AISI 1020 steel cage (Figure 8), disappears the phase $\mathrm{FeCr}$ and appears the phase $\mathrm{Fe} 3 \mathrm{O} 4$ (iron oxide) coming from the cage.

The samples which were treated in NGC with stainless steel cage have shown a small nitride $\varepsilon$ formation, it is possibly due to the low carbon content in the cathodic cage.

The $\mathrm{x}$-ray diffraction patterns reveal a variation in relative intensities of the nitrides peaks $\varepsilon, \gamma^{\prime}, \varepsilon+\gamma$ of samples with different nitrided heights by DCPN process. This variation of intensity of the peaks is due to a temperature variation between sample's surface and the sample holder ${ }^{8}$. As there is a uniformity of temperature in

\section{References}

1. Alves C Jr. Nitretação a plasma: Fundamentos e Aplicações. Natal: EDUFRN; 2001.

2. Li CX and Georges, XY LI. Active screen plasma nitriding of austenitic stainless steel. Surface Engineer. 2002; 18(6):453458. http://dx.doi.org/10.1179/026708402225006240

3. Li CX and Bell T. Corrosion properties of active screen plasma nitrided 316 austenitic stainless steel. Corrosion Science. 2004; 46:1527-1547. http://dx.doi.org/10.1016/j. corsci.2003.09.015

4. Alves C Jr, Silva EF and Martinelli AE. Effect of workpiece geometry on the uniformity of nitrided layers. Surface and Coatings Technology. 2001; 139(1):1-5. http://dx.doi. org/10.1016/S0257-8972(00)01146-4

5. Alves C Jr, De Araújo FO, Ribeiro KJB, Da Costa JAP, Sousa RRM and De Sousa RS. Use of cathodic cage in plasma nitriding. Surface \& Coatings Technology. 2006; 201(6): 24502454. http://dx.doi.org/10.1016/j.surfcoat.2006.04.014 the NGC process, there is no variation with the samples height of the relative intensities of the peaks of the nitrides which were mentioned above, as it can be proved through $\mathrm{x}$-ray diffraction patterns Bragg-Bretano. The temperature is uniform since the samples are in a floating potential and they are heated by radiation from cathodic cage.

\section{Conclusions}

In the nitriding in cathodic cage (NGC) technique, samples with different height which were nitrided together do not show significant variation of layer thickness and they also show similar microhardness. In addition, the superficial microhardness of samples which were treated in cathodic cage is uniform along the surface; it proves the elimination of edge effects. Besides eliminating undesirable phenomenon, such as opening arc and hollow cathode effect, in samples with holes and edges they will occur in the cathodic screen instead of sample's surface.

The nitriding with cathodic cage technique is presented as new tool extremely versatile, avoiding problems traditionally associated with plasma nitriding. The deposition effect is greatly enhanced in this technique, as it was shown in FeCr deposition with AISI 316 steel cage and in Fe3O4 deposition with AISI 1020 steel cage. It is also highlight the wide variety of films that can be deposited, being enough just a variation in the cage's material which could be, graphite, titanium and copper.

\section{Acknowledgements}

The authors thank CAPES, CNPQ and IFPI by the grant of PIBIC and PROAGRUPAR scholarships.

6. Li CX and Bell T. Principles, mechanisms and aplications of active screen plasma nitriding. Heat Treatment of Metals. 2003; 30(1):1-7.

7. Ruset C, Ciuca S, Grigore E. The influence of the sputtering process on the constitution of the compound layers obtained by plasma nitriding. Surface and Coatings Technology. 2003; 174 175:1201-1205. http://dx.doi.org/10.1016/S02578972(03)00589-9

8. Sousa RS. Influência da geometria de peças e parâmetros do processo sobre as caracteróstica da camada nitretada por plasma. [Tese]. Natal: Universidade Federal do Rio Grande do Norte; 2005.

9. Lima JA. Influência do gradiente térmico e da taxa de resfriamento na formação da camada nitretada a plasma. [Tese]. Natal: Universidade Federal do Rio Grande do Norte; 2003. 